\title{
O percurso histórico do ensino médio no Brasil: uma reflexão sobre as políticas públicas de avaliação educacional
}

Fábio Alexandre Ferreira Gusmão ${ }^{1}$

Simone Silveira Amorim ${ }^{2}$

\section{Resumo}

Este artigo tem como objetivo analisar os principais marcos legais que regulamentam o Ensino Médio a partir da Constituição de 1988. Além disso, foi feita uma reflexão sobre as políticas públicas de avaliação educacional. A pesquisa foi de abordagem qualitativa e utilizou a pesquisa bibliográfica como método de investigação. Foi feita a partir da análise dos tipos de leis provenientes da Constituição de 1988, e das pesquisas empíricas oriundas das avaliações em larga escala. A partir da análise do percurso histórico do Ensino Médio no Brasil, a partir de 1996, observa-se que o Sistema de Avaliação da Educação Básica (SAEB) pode contribuir para a melhoria da qualidade da educação escolar.

Palavras-chave: Avaliação Educacional; Ensino Médio; SAEB.

\section{The historical travel of high school in Brazil: a reflection on public policies of educational evaluation}

\section{Abstract}

This article aims to analyze the main legal frameworks that regulate secondary education from the 1988 Constitution on. In addition, a reflection was made on public policies of educational evaluation. The research, based on the qualitative approach, made used of bibliographic research as method, and it was based on the analysis of the types of laws deriving from the 1988 Constitution as well as empirical researches on large-scale evaluations. From the analysis of the historical course of High School in Brazil, as of 1996, it can be observed that the Evaluation System of Basic Education (SAEB) can contribute to the improvement of the quality of school education.

Keywords: Educational Evaluation; Secondary School; SAEB.

\section{Introdução}

Com a promulgação Constituição de 1988 (BRASIL, 1988) e a Lei de Diretrizes e Bases da Educação Nacional - LDB/1996 (BRASIL, 1996) foi possível a implementação de políticas públicas de avaliação educacional que foram impulsionadas com a redemocratização ocorrida a partir da década de 1980 (BAUER; TAVARES, 2013; FREITAS, 2013; BONAMINO, 2002).

Atualmente, no Brasil, o Sistema de Avaliação Educacional é organizado da seguinte forma: Sistema de Avaliação da Educação Básica (SAEB), composto por provas de Língua

\footnotetext{
${ }^{1}$ Universidade Tiradentes/UNIT, Aracaju, fa_bio_gus@hotmail.com.

${ }^{2}$ Universidade Tiradentes/UNIT, Aracaju, amorim_simone@hotmail.com.
} 
Portuguesa e Matemática para estudantes do 2ㅇ, 5ㅇ e 9o ano do Ensino Fundamental, e da 3a e 4a série do Ensino Médio (tradicional e integrado). Em 2019 os alunos do 9o ano do Ensino Fundamental fizeram provas de Ciências da Natureza e Ciências Humanas; Exame Nacional do Ensino Médio (ENEM), avaliação individual do desempenho feita ao final do Ensino Médio; Exame Nacional para Certificação de Competências de Jovens e Adultos (ENCCEJA), avaliação direcionada a jovens e adultos para certificação dos participantes, em nível de conclusão do Ensino Fundamental ou Ensino Médio; e Exame Nacional de Desempenho de Estudantes (ENADE), que avalia o rendimento dos concluintes dos cursos de graduação.

Desta forma, o atual Sistema Nacional de Avaliação vem se organizando de "[...] forma progressiva, expansiva e diversificada no curso de cinco gestões [...] governamentais no país" (FREITAS, 2013, p.71). Com o propósito de consolidar o atual sistema de avaliação e monitoramento da educação escolar e produzir subsídios para a elaboração de políticas públicas de avaliação.

Portanto, a consolidação do atual Sistema Nacional de Avaliação vai possibilitar produzir dados e evidências estatísticas que podem ser utilizadas nas pesquisas no campo da avaliação educacional, o que contribui para o aperfeiçoamento dos processos educativos relacionados com a aprendizagem escolar.

Para traçar a trajetória histórica das políticas públicas de avaliação educacional no Brasil, tomamos como ponto de partida, algumas experiências pioneiras de avaliação educacional da aprendizagem escolar dos alunos, buscando identificar os principais fatores que poderiam afetar o desempenho escolar dos estudantes. Como exemplo, podemos citar os projetos e pesquisas empíricas no campo da avaliação educacional, descritos a seguir.

O primeiro, foi um conjunto de avaliações de desempenho escolar realizado pela Fundação Getúlio Vargas do Rio de Janeiro, no Centro de Estudos de Testes e Pesquisas Psicológicas CE-TPP, realizado em 1960. Estas avaliações foram aplicadas nas últimas séries do Ensino Médio, nas áreas de Linguagem, Matemática, Ciências Físicas e Naturais e Estudos Sociais. Elas também coletavam informações sobre diversas variáveis socioeconômicas para que se pudesse estabelecer relação com a aquisição das disciplinas avaliadas (GATTI, 2009).

Acreditamos que a aplicação dessas avaliações marcou o surgimento, no Brasil, das pesquisas no campo da avaliação educacional que utilizaram teorias, processos, métodos e 
instrumentos específicos para avaliar o desempenho dos estudantes; e verificar a relação entre a aquisição dos conhecimentos adquiridos na escola com diferentes variáveis como: sexo, nível socioeconômico etc.. (GATTI, 2009).

Na década de 1980, foi desenvolvida uma pesquisa sobre os resultados da aprendizagem escolar resultante do Programa de Expansão e Melhoria do Ensino no Meio Rural do Nordeste Brasileiro (Edurural). Este programa foi criado em 1977 e buscava a melhoria do ensino da zona rural dos estados do nordeste brasileiro, por meio da implementação de uma série de ações que contemplavam a capacitação de pessoal, a assistência técnica e a produção de material didático. A pesquisa foi conduzida por pesquisadores da Fundação Carlos Chagas (GATTI; VIANNA; DAVIS, 1991; GATTI, 1994).

A pesquisa descrita anteriormente, consistiu em um estudo transversal, com coleta de dados em 1981, 1983 e 1985 nos estados do Piauí, Pernambuco e Ceará. O estudo investigou o efeito de diversas variáveis (condições da escola, merenda escolar, perfil dos professores, impacto de treinamentos, condições das famílias dos alunos) sobre o desempenho escolar. Os testes foram aplicados a todas as crianças da $2^{a} \underline{a}$ e $4^{a}$ série (atual, $3^{\circ}$ e $4^{\circ}$ anos do Ensino Fundamental) para as disciplinas de Língua Portuguesa e Matemática.

Os principais resultados apresentados pelos autores destacam que, mesmo com o grande aporte de investimento em construções, reformas, treinamentos, produção de material didático etc. do programa Edurural, não houve melhoria significativa no desempenho escolar ao longo dos anos. Posteriormente, com estudos etnográficos em municípios dos três estados mencionados, foi possível encontrar alguns fatores que poderiam ter contribuído para este resultado tais como: alta rotatividade dos professores, ausência de uma política de contratação, efetivação e valorização do salário do professor, mas também falta de garantia dos recursos financeiros constantes para aquisição de material didático e merenda escolar.

O programa de avaliação do rendimento escolar de $1^{\circ}$ grau, realizado em 1987 avaliou os estudantes de todo território nacional. A investigação foi realizada nas escolas públicas indicadas pelas secretarias de educação dos estados. Esse programa aplicou provas de Português e Matemática para os estudantes da 1ạ e 3 ạ séries (atuais, $2^{\circ}$ e $4^{\circ}$ ano do Ensino Fundamental), mas também Português, Matemática, Ciências e Redação para os estudantes das $5 \underline{a}$ e $7 \underline{a}$ séries (atuais, $6^{\circ}$ e $8^{\circ}$ ano do Ensino Fundamental) (GATTI; VIANNA; DAVIS, 1991; GATTI, 1994). 
Os resultados das pesquisas citadas anteriormente demonstraram que o rendimento dos estudantes foi muito baixo, mas também se observou um elevado percentual de reprovação. Além disso, a pesquisa identificou os conhecimentos acadêmicos em que os alunos tinham mais dificuldades. Isto foi feito para que posteriormente se pudesse propor medidas para a melhoria da aprendizagem escolar. Portanto, a partir dos resultados encontrados, foi possível elaborar uma nova proposta curricular que foi discutida com os professores e implantada na rede de ensino.

Uma das primeiras pesquisas empíricas realizadas no Brasil utilizando os dados do SAEB foi a de Soares, Cesar e Manbrini (2001), que analisaram os dados de provas de Matemática da 8a série do Ensino Fundamental do SAEB de 1997, utilizando análise de regressão multinível. A pesquisa teve como objetivo encontrar os fatores explicativos do desempenho dos alunos brasileiros da 8a série do SAEB de 1997 na prova de Matemática. Logo, nessa pesquisa, os autores identificaram fatores explicativos por meio da obtenção de dados relacionados à característica do aluno, da escola, do professor e do diretor que se relacionam com o desempenho escolar.

As principais conclusões dos autores sobre os fatores explicativos relacionados ao desempenho escolar destacam que, os alunos com melhor condição socioeconômica, trajetória escolar regular (sem reprovações e sem abandono da escola), do sexo masculino e das escolas particulares são os que apresentam o melhor desempenho escolar.

A partir destas experiências iniciais de avaliação da educação escolar foi possível identificar e conhecer alguns fatores que se relacionam com o desempenho escolar brasileiro. Desta forma, estas avaliações iniciais permitiram produzir informações, dados e evidências que subsidiaram a construção do atual Sistema Nacional de Avaliação da Educação Básica.

Diante de tais considerações, este artigo tem como objetivo analisar os principais marcos legais que regulamentam o Ensino Médio a partir da Constituição de 1988 (BRASIL, 1988). Além disso, foi feita uma reflexão sobre as políticas públicas de avaliação. A pesquisa foi de abordagem qualitativa e utilizou a pesquisa bibliográfica como método de investigação. Foi feita a partir da análise dos tipos de leis provenientes da Constituição de 1988 (BRASIL, 1988) e das pesquisas empíricas oriundas das avaliações em larga escala. 


\section{Contexto histórico dos principais marcos legais que regulamentam o ensino médio, a partir} da Constituição de 1988

A Constituição da República Federativa do Brasil, promulgada em 5 de outubro de 1988 (BRASIL, 1988), possibilitou a implantação de diversos direitos sociais, políticos e educacionais, além de estabelecer o sistema federativo com a descentralização das políticas sociais e educacionais para os estados, municípios e o distrito federal (ASSIS; SILVA, 2017). Além disso, a Constituição de 1988 "é a mais extensa em todas de matéria de educação" (VIEIRA, 2007, p.304) porque apresenta os princípios básicos da educação que estão contidos no capítulo III (educação, da cultura e do desporto), e na seção I (da educação).

No Brasil, somente a partir do século XX, com a promulgação da Constituição Federal de 1988 (BRASIL, 1988), a educação escolar passou a ser um dever do Estado, devendo ser ministrada com base no princípio de que todos os brasileiros tenham igualdade de condições de acesso e permanência na escola.

Logo, com a promulgação da lei 12.796, de 4 abril de 2013 (BRASIL, 2013), e da Emenda Constitucional $n^{\circ}$ 59, de 11 de novembro do 2009 (BRASIL, 2009), a educação básica se tornou obrigatória e gratuita dos quatro aos dezessete anos de idade, inclusive para todos os que não tiveram acesso a ela na idade adequada, o que garantiu o acesso público e gratuito ao Ensino Médio.

A partir da Constituição de 1988 (BRASIL, 1988) e da LDB/1996 (BRASIL, 1996) foi possível a implementação de políticas públicas e marcos legais, como: o terceiro Plano Nacional de Educação - PNE (BRASIL, 2014), que está referido no art. 214 da Constituição Federal de 1988; o Fundo de Manutenção e Desenvolvimento da Educação Básica e de valorização dos profissionais da educação- FUNDEB (BRASIL, 2007); a Lei no 11.274 (BRASIL, 2006), que estabeleceu a obrigatoriedade do ensino fundamental com duração de 9 (nove) anos, com matrícula obrigatória a partir dos 6 (seis) anos de idade.

Em relação ao Ensino Médio, a LDB/1996 (BRASIL, 1996) estabeleceu, no artigo 35, que é a "etapa final da educação básica", pois a Constituição de 1988 (BRASIL, 1988) já prenunciava, no inciso II do artigo 208, a obrigatoriedade e a gratuidade do Ensino Médio, conferindo a este o estatuto de direito de todo o cidadão. Mas, a partir da LDB/1996 (BRASIL, 1996), o Ensino Médio passou a ter as seguintes finalidades, descritas no artigo 35: 
I - a consolidação e o aprofundamento dos conhecimentos adquiridos no ensino fundamental, possibilitando o prosseguimento de estudos;

II - a preparação básica para o trabalho e a cidadania do educando, para continuar aprendendo, de modo a ser capaz de se adaptar com flexibilidade a novas condições de ocupação ou aperfeiçoamento posteriores;

III - o aprimoramento do educando como pessoa humana, incluindo a formação ética e o desenvolvimento da autonomia intelectual e do pensamento crítico; IV - a compreensão dos fundamentos científico-tecnológicos dos processos produtivos, relacionando a teoria com a prática, no ensino de cada disciplina.

A Lei 12.796 de 4 abril de 2013 (BRASIL, 2013), tornou a educação básica obrigatória e gratuita dos quatro aos dezessete anos de idade e garantiu acesso público e gratuito ao ensino Fundamental e Médio para todos os que não os concluíram na idade própria. Portanto, essa lei basicamente adequou a redação LDB/1996 (BRASIL, 1996) à Emenda Constitucional no 59, de 11 de novembro do 2009 (BRASIL, 2009), que tornou o Ensino Médio obrigatório e gratuito dos quatro a dezessete anos, inclusive para todos os que não tiveram acesso a ela na idade adequada. Ressaltamos que também ampliou a abrangência dos programas suplementares de material didático escolar, transporte, alimentação e assistência à saúde para todas as etapas da educação básica.

Desse modo, essa lei ampliou a gratuidade e a obrigatoriedade para o Ensino Médio e estabeleceu o prazo limite até 2016 para que municípios e Estados estruturassem suas redes de ensino e oferecessem vagas suficientes para atender todos os adolescentes que ainda não estivessem frequentando a escola.

Silva e Scheibe (2017, p.21) destacam, que o Ensino Médio tem "[...] sido alvo de disputas - que se acirram nos últimos 20 anos", o que pode ser percebido com a reforma do Ensino Médio implementada com a publicação da lei no 13.415, de 16 de fevereiro de 2017 (BRASIL, 2017), na qual se alteram as diretrizes e bases da educação nacional, o financiamento do ensino e a qualificação para o exercício da docência. Logo, a reforma proposta visa adequar o Ensino Médio a uma lógica pragmática e mercantil do ensino público, a partir de parcerias com instituições privadas, no qual se pretende privilegiar uma formação profissional em detrimento de um Ensino Médio propedêutico inclusivo e universal.

A lei no 13.415 (BRASIL, 2017) aprovou a reforma do Ensino Médio e instituiu a política de fomento à escolas em tempo integral. Deste modo, das mudanças introduzidas no Ensino Médio, destacam-se: 
1. Aumento da carga horária anual (artigo 1, parágrafo 1). A carga horária mínima anual deverá ser ampliada de forma progressiva, no Ensino Médio, para mil e quatrocentas horas, devendo os sistemas de ensino oferecer, no prazo máximo de cinco anos, pelo menos mil horas anuais de carga horária, a partir de 2 de março de 2017;

2. Determinação de padrões mínimo esperados a partir da Base Nacional Comum Curricular (artigo 3, parágrafo 8). Define que a União estabelecerá os padrões de desempenho esperados para o Ensino Médio, que serão referência nos processos nacionais de avaliação, a partir da Base Nacional Comum Curricular;

3. Construção do currículo fundamentado na Base Nacional Comum Curricular (artigo 4).

Estabelece que o currículo do Ensino Médio será composto pela Base Nacional Comum Curricular e por itinerários formativos, que deverão ser organizados por meio da oferta de diferentes arranjos curriculares, conforme a relevância para o contexto local e a possibilidade dos sistemas de ensino, a saber: I - linguagens e suas tecnologias; II - matemática e suas tecnologias; III - ciências da natureza e suas tecnologias; IV - ciências humanas e sociais aplicadas - formação técnica e profissional (BRASIL, 2017).

4. Parcerias com instituições de educação escolar que ofereçam ensino a distância (artigo 4, parágrafo 11$)$.

\begin{abstract}
Para efeito de cumprimento das exigências curriculares do Ensino Médio, os sistemas de ensino poderão reconhecer competências e firmar convênios com instituições de educação a distância com notório reconhecimento, mediante as seguintes formas de comprovação: I - demonstração prática; II - experiência de trabalho supervisionado ou outra experiência adquirida fora do ambiente escolar; III - atividades de educação técnica oferecidas em outras instituições de ensino credenciadas; IV - cursos oferecidos por centros ou programas ocupacionais; $V$ - estudos realizados em instituições de ensino nacionais ou estrangeiras; VI - cursos realizados por meio de educação a distância ou educação presencial mediada por tecnologias (BRASIL, 2017).
\end{abstract}

5. Exercício profissional do docente do Ensino Médio sem formação em instituições de educação superior (artigo 6, inciso 4).

Profissionais com notório saber reconhecido pelos respectivos sistemas de ensino, para ministrar conteúdos de áreas afins à sua formação ou experiência

Periódico Horizontes - USF - Itatiba, SP - Brasil - e020022 
profissional, atestados por titulação específica ou prática de ensino em unidades educacionais da rede pública ou privada ou das corporações privadas em que tenham atuado (BRASIL, 2017).

A lei no 13.415 (BRASIL, 2017) ao permitir o exercício docente para os "profissionais com notório saber [...]" desconsidera toda a trajetória histórica de consolidação da profissão docente no Brasil. Visto que, a profissão docente foi sendo consolidada ao longo do tempo por meio do reconhecimento de um estatuto de profissionalidade plena na qual se reconhecem, afirmam-se e são distinguidas na representação social pela posse de um saber próprio, distinto e exclusivo do grupo que o partilha, produz e faz circular, conhecimento esse que legitima o exercício da sua atuação profissional.

Portanto, quando a lei no 13.415 (BRASIL, 2017) propôs o exercício profissional docente sem a formação obrigatória na educação superior, ela entrou em divergência com a LDB/1996 (BRASIL, 1996) que exige a formação em licenciatura ou pedagogia em instituições de educação superior para atuar no magistério da educação básica.

Deste modo, além dessa formação inicial determinada em lei, faz-se necessário outras competências, tais como: conhecimento especializado; autonomia intelectual e pedagógica; prestígio, reconhecimento e valorização social e econômica; controle de qualidade dos procedimentos pedagógicos inerentes à prática pedagógica; código de ética que exponha os princípios e a missão da atividade profissional do professor.

Das pesquisas empíricas que destacam o efeito positivo da formação inicial em instituições de ensino superior para o exercício profissional dos professores, vale ressaltar o estudo de Almeida (2014), que analisou os dados do teste de Língua Portuguesa e Matemática do $5^{\circ}$ e $9^{\circ}$ do Ensino Fundamental da Prova Brasil de 2011. A pesquisa teve como objetivo avaliar os fatores que mais contribuem para a performance dos alunos de escolas da rede pública de ensino fundamental nos exames padronizados de Português e Matemática.

O resultado encontrado pelo autor destaca o efeito positivo da equipe de docentes mais experientes, com pelo menos seis anos de experiência em uma mesma turma e/ou disciplina sobre o desempenho escolar verificado pelo resultado da Prova Brasil. Mas também aponta a contribuição da formação superior e da formação continuada para a melhoria do desempenho escolar, fato identificado nos testes de Língua Portuguesa e Matemática. 
Logo, os marcos legais que regem a formação inicial dos professores permitiu uma profissionalização docente por meio da construção de saberes profissionais oriundos de sua formação inicial na educação superior e da consolidação de uma trajetória profissional histórica de construção da carreira docente no Brasil.

Todavia, independente das controvérsias e consonâncias que envolvem a reforma do Ensino Médio proposto pela lei no 13.415 (BRASIL, 2017), torna-se necessário ressaltar que o Ensino Médio vem reduzindo o número de matrículas. Em 2004 foram 9.169.357 matrículas, passando para, 7.125.365 em 2018, o que significa que nesse período houve uma redução de 22,3\%, das matrículas no Ensino Médio propedêutico, enquanto no mesmo período houve um crescimento de 676.093 para 1.903.230, respectivamente para educação profissional, de acordo com o Censo Escolar do INEP em 2018 (BRASIL, 2019).

Assim, a redução das matrículas no Ensino Médio propedêutico, e o aumento na Educação Profissional podem ser explicados, em parte, pela expansão no Ensino Médio na modalidade da Educação de Jovens e Adultos, e pelo aumento da oferta da Educação Profissional de forma concomitante e subsequente ao Ensino Médio regular. Uma vez que, políticas públicas de acesso à Educação Profissional, e a baixa qualidade do Ensino Médio ofertado aos estudantes durante a sua trajetória na educação escolar contribuem para que a Educação Profissional exerça uma maior atração entre os jovens em idade escolar; o que colabora para que os estudantes de origem econômica pobre prefiram a Educação Profissional em detrimento a um Ensino Médio propedêutico.

A análise histórica do Ensino Médio brasileiro vem demonstrando como ocorreu a segmentação desse nível de ensino, no qual os pobres cursam as escolas de Ensino Médio público e/ou profissionalizante, enquanto os ricos estudam nas escolas de Ensino Médio particular e propedêutico. Isto posto, nota-se que as escolas são segmentadas pela condição econômica, o que pode ser verificado mais detalhadamente em diversas pesquisas empíricas brasileiras (ALBERNAZ; FERREIRA; FRANCO, 2002; ALVES, 2008; RIBEIRO, 2011; SOARES; MAROTTA, 2009) que analisaram o efeito do nível socioeconômico na estratificação dos alunos da Educação Básica por critérios econômicos.

Consequentemente, tais fatores têm direcionado o Ensino Médio a atender as demandas do mercado de trabalho, o que, de acordo com Silva e Scheibe (2017, p.27) “[...] configura-se, 
assim, a hegemonia de uma perspectiva pragmática e mercantilizada do Ensino Médio público"; que serve para a construção de um sistema de ensino que encaminha os estudantes das classes médias altas para o Ensino Médio propedêutico, enquanto que os estudantes das classes pobres vão para a Educação Profissional de nível médio.

Portanto, a estratificação escolar promove a desigualdade de oportunidades educacionais na medida em que o aluno com maior condição econômica, ou cujos pais se sacrificam financeiramente para tentar provê-lo com uma educação de melhor qualidade, frequenta as escolas privadas de ensino propedêutico, o que contribui para que tenham mais chances de progredir na educação escolar do que os alunos pobres, que cursam as escolas públicas e profissionalizantes. Desta forma, a Educação Profissional atende, prioritariamente, aos alunos pobres, visto que eles estudaram o Ensino Médio nas escolas públicas, o que acaba diminuindo a sua probabilidade de acesso às universidades públicas e às profissões que permitem um emprego com maior prestígio social e econômico.

A pesquisa de Gonçalves e França (2008) analisou os dados do SAEB de 2003 de Matemática dos alunos de 4a série do ensino fundamental e 3o ano do Ensino Médio. A pesquisa teve como objetivo mostrar como a desigualdade é reproduzida no sistema educacional, isto é, como a escola, ao não se mostrar neutra, perpetua as desigualdades escolares.

Além disso, buscou os fatores que explicam a qualidade escolar no nível individual, escolar e estadual, assim como a sua elevação possibilitaria à escola agir como instrumento de ruptura entre o baixo nível socioeconômico da família e o baixo desempenho escolar dos filhos.

De acordo com os autores, a frequência dos estudantes às escolas particulares e federais, a presença de uma boa infraestrutura de equipamentos e de segurança, ser do sexo masculino, ter se autodenominado branco, aumento dos recursos em relação ao PIB e o percentual de votantes no 1ㅇ turno nas eleições de 2002 demonstraram ter um efeito positivo sobre o desempenho escolar.

A principal conclusão da pesquisa é que as diferenças de condições observadas (no nível individual, escolar e estadual) mostram ter impacto no desempenho escolar. Portanto, a qualidade das escolas (principalmente aquelas do Ensino Médio) pode reduzir estes impactos, entretanto as desigualdades sociais, econômicas e educacionais entre os estados podem dificultar à democratização do ensino de qualidade. 
Por fim, o estudo de Soares e Marotta (2009), que investigou empiricamente as desigualdades da educação básica brasileira a partir dos dados de Leitura e Matemática do SAEB de 1997, 1999, 2001 e 2003, nas 4a e 8a séries do Ensino Fundamental, verificaram que o Ensino Fundamental reproduz a desigualdade econômica e social presente na sociedade brasileira.

Os autores indicam que as diferenças observadas entre o desempenho escolar refletem as desigualdades econômicas e sociais existentes entre os alunos. Logo, o Ensino Fundamental tem um maior problema de qualidade [que na pesquisa foi considerada como sendo o desempenho escolar verificado pelo SAEB], do que entre os fatores relacionadas ao sexo, grupo étnico e nível socioeconômico. Ou seja, os resultados encontrados demonstram que o capital cultural, social e econômico do aluno e a segmentação da escola (pública e particular) explicam as diferenças de desempenho escolar.

Os resultados das pesquisas citadas anteriormente demonstram que, no Brasil, as condições econômicas e sociais são fatores importantes que se relacionam com o desempenho escolar verificado pelo SAEB. Por isto existe a necessidade de políticas públicas sociais, econômicas e educacionais que contribuam para a diminuição da pobreza e da desigualdade social, econômica e educacional; o que afeta indiretamente a melhoria da aprendizagem escolar e, consequentemente, o desempenho escolar verificado pelas avaliações em larga escala.

Ademais, observa-se que, no Brasil, segundo o IBGE (BRASIL, 2014), o acesso da população de 15 a 17 anos ao Ensino Médio foi de 85,0\%, o que significa que 15,0\%, da população dessa faixa etária ainda não teve acesso a essa etapa da educação básica, mesmo com o direito garantido pela Constituição de 1988. Por isso, a igualdade de acesso e permanência ao Ensino Médio fica comprometido pela ausência de políticas públicas que considerem a origem socioeconômica, familiar, étnica e regional do indivíduo para a inclusão dos jovens na educação escolar.

Curi e Menezes-Filho (2009) analisaram a relação entre a educação pré-primária (creche e pré-escola) e os salários, a escolaridade e a proficiência escolar no Brasil. Eles utilizaram os dados da Pesquisa de Padrão de Vida, realizada pelo IBGE entre março de 1996 e março de 1997 nas regiões Nordeste e Sudeste do Brasil, e os do SAEB dos estudantes da 4ạ e 8aa série do ensino fundamental e $3^{\circ}$ ano do Ensino Médio em Matemática.

Os autores mostram que a pré-escola tem um efeito positivo e significativo para a conclusão dos estudantes da 4a e 8a série do ensino fundamental e da 3ạ série do Ensino Médio. 
Além disso, a pré-escola também contribui para que os estudantes tenham um desempenho escolar melhor, verificado pelo SAEB. Também apresenta uma relação positiva e significante com a renda do trabalho principal, já que as pessoas que iniciaram os estudos com idade entre 4 e 6 anos ganham, em média, salário mais elevado que os demais.

Portanto, as políticas educacionais e os marcos legais implementados no Brasil precisam propor programas, alternativas e normas que contemplem a educação infantil para que, dessa forma, contribuam para corrigir os fatores individuais, sociais, educacionais e econômicos que prejudicam o desempenho escolar verificado pelo SAEB, como também oportunizar as condições necessárias para que os estudantes alcancem e concluam o Ensino Médio e a Educação Superior. É neste sentido que se insere a importância do Sistema Nacional de Avaliação da Educação Básica, pois se propõe a servir de instrumento de avaliação, acompanhamento e proposição de políticas públicas efetivas para a educação Brasileira.

\section{Política pública de avaliação educacional no Brasil}

Com a aprovação do terceiro PNE (BRASIL, 2014), com vigência de 10 (dez) anos, que propõe a "melhoria da qualidade do ensino" (art. 1, inciso IV) por meio do Sistema Nacional de Avaliação da Educação Básica, determinou-se, com o art. 11, que:

O Sistema Nacional de Avaliação da Educação Básica, coordenado pela União, em colaboração com os Estados, o Distrito Federal e os Municípios, constituirá fonte de informação para a avaliação da qualidade da educação básica e para a orientação das políticas públicas desse nível de ensino.

Dessa forma, o Sistema Nacional de Avaliação da Educação Básica vem com a finalidade de aferir a aprendizagem dos alunos e o desempenho das escolas da educação básica e prover informações para avaliação e revisão de planos e programas de qualificação educacional. Uma das diretrizes do PNE (BRASIL, 2014, art. 5) é que "a execução do PNE e o cumprimento de suas metas serão objeto de monitoramento contínuo e de avaliações periódicas [...]", o que destaca a importância dos sistemas de informação e de avaliação para o acompanhamento da realidade da educação escolar no país. 
Desta forma, a organização de sistemas avaliativos de estudantes da educação básica pela União, objetivando a definição de prioridades e a melhoria da qualidade do ensino, é prerrogativa estabelecida pela LDB no 9.394 de 1996 (BRASIL, 1996) que diz, no artigo 9o, parágrafo 6으, que se deve: “[...] assegurar processo nacional de avaliação do rendimento escolar no ensino fundamental, médio e superior, em colaboração com os sistemas de ensino, objetivando a definição de prioridades e a melhoria da qualidade do ensino". Destaca como objetivos a definição de prioridades e a melhoria da qualidade do ensino, enfatizando ainda como responsabilidade dos estados a avaliação dos estabelecimentos do seu sistema de ensino.

Com a criação do Instituto Nacional de Estudos e Pesquisas Educacionais Anísio Teixeira - INEP (BRASIL, 1997) em 1997, passa a existir uma preocupação com a qualidade do ensino no Brasil, que passou a ser verificada por um sistema de avaliação e monitoramento da educação escolar, que permite uma análise dos processos educativos, possibilitando seu aprimoramento e consequente busca pela garantia da qualidade.

A partir do decreto no 9.432 de 29 de junho de 2018 (BRASIL, 2018) ocorreu a regulação da Política Nacional de Avaliação e Exames da Educação Básica, que tem como objetivos:

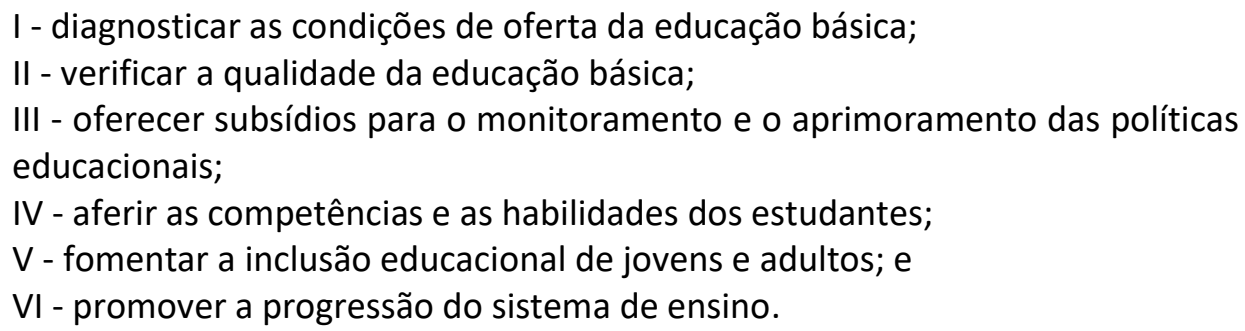

Além disso, o decreto integra na Política Nacional de Avaliação e Exames da Educação Básica: o Sistema de Avaliação da Educação Básica - SAEB; o Exame Nacional para Certificação de Competências de Jovens e Adultos - ENCCEJA; o Exame Nacional do Ensino Médio - ENEM (BRASIL, 2018, art.4).

Ademais, define o SAEB como "um conjunto de instrumentos que permite a produção e a disseminação de evidências, estatísticas, avaliações e estudos a respeito da qualidade das etapas que compõem a educação básica [...]"(BRASIL, 2018, art. 5), que é composto por um conjunto de avaliações externas em larga escala que permite realizar um diagnóstico a partir da coleta de dados sobre alunos, professores e diretores de escolas públicas e particulares que 
podem influenciar o desempenho dos estudantes.

Atualmente, com a portaria 366 (BRASIL, 2019), o SAEB passou a ser composto por provas de Língua Portuguesa, Matemática, Ciências da Natureza e de Ciências Humanas que são aplicadas aos estudantes do 2으, 5으 e 9o anos do Ensino Fundamental e da 3a e 4a séries do Ensino Médio (tradicional e integrado).

No tocante às escolas públicas, trata-se de uma avaliação censitária em que todos os

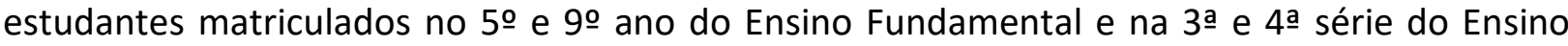
Médio (tradicional e integrado), localizadas em zonas urbanas e rurais que possuam 10 (dez) ou mais estudantes, respondem as provas de Língua Portuguesa e Matemática.

Com relação às escolas privadas, participam os estudantes provenientes de uma amostra de escolas localizadas em zonas urbanas e rurais que possuam 10 (dez) ou mais estudantes matriculados em turmas de 5o e 9o ano do Ensino Fundamental e de 3a e 4a série do Ensino Médio (tradicional e integrado), sendo aplicadas provas de Língua Portuguesa e Matemática.

No que concerne à aplicação das provas aos estudantes oriundos de uma amostra de escolas públicas e privadas localizadas em zonas urbanas e rurais que possuam 10 (dez) ou mais estudantes matriculados, foram aplicadas provas de Língua Portuguesa e Matemática para 2o ano do Ensino Fundamental e de Ciências da Natureza e Ciências Humanas para o 9o ano do mesmo nível de ensino.

Portanto, com a publicação da portaria no 366, de 02 de maio de 2019 (BRASIL, 2019) foi instituído as diretrizes para a avaliação em larga escala. Além disso, ela estabeleceu como principais objetivos: avaliar a qualidade e eficiência da educação básica, fornecer subsídios para elaboração de políticas públicas e concorrer para a melhoria da qualidade do ensino e redução das desigualdades educacionais.

A partir de 1995, o SAEB passou a adotar a Teoria de Resposta ao Item (TRI) para analisar os resultados de suas avaliações. A TRI é um conjunto de modelos matemático que procuram representar a probabilidade de um indivíduo dar uma certa resposta a um item, como função dos parâmetros do item para os traços latentes dos respondentes. Esses traços latentes procuram representar a relação entre a probabilidade de um aluno responder corretamente a um item e sua real habilidade e/ou competência em fazê-lo. Tal procedimento permite a criação de escalas que são definidas por meio de níveis os quais são descritos a partir da identificação 
dos itens-âncora, que auxiliam na interpretação do que os alunos sabem e são capazes de fazer em cada nível da escala (VALLE, 2001).

Dessa forma, a interpretação da escala de proficiência permite aferir o que os estudantes aprenderam, porque possibilita o monitoramento da realidade da educação escolar, além de permitir a produção de indicadores educacionais que vão subsidiar o planejamento e aprimoramento das políticas públicas de avaliação educacional, e consequentemente das ações pedagógicas para os sistemas de ensino, escolas e docentes.

\section{Considerações finais}

O Ensino Médio brasileiro é a etapa final da educação básica, portanto é o estágio da educação escolar, que ocorre a aquisição dos conhecimentos escolares, e o desenvolvimento das competências; para que os jovens possam buscar na Educação Profissional sua inserção no mercado de trabalho e/ou prosseguir sua formação acadêmica na educação superior.

No Brasil, observa-se que só a partir de 1990 o acesso à Educação Básica, formada pela Educação Infantil, Ensino Fundamental e Ensino Médio passou a ser universalizado, obrigatório e gratuito dos quatro aos dezessete anos de idade; mas também foi garantido o acesso para todos os que não concluíram na idade própria, sendo um direito garantido pela Constituição de 1988.

Deve-se salientar que, "qualquer política educacional, verdadeiramente igualitária, terá que dar ênfase aos primeiros anos de escolaridade e, mais do que isso, tentar educar a criança antes que ela chegue à escola primária [...]" (CASTRO, 1976, p.81) para que, desta forma, possa contribuir para corrigir os fatores individuais, sociais, econômicos e políticos que interferem na trajetória do estudante brasileiro na educação básica.

A partir da análise dos principais marcos legais que regulamentam o Ensino Médio a partir da Constituição de 1988 e das políticas públicas de avaliação, observa-se que o SAEB pode contribuir para a melhoria da qualidade da educação escolar no Ensino Médio; desde que possa produzir subsídios para a elaboração de políticas públicas para a melhoria do desempenho escolar, mas também gerar indicadores educacionais que permitam seu monitoramento e adequação à população jovem, que pretende cursar o Ensino Médio, seja ele propedêutico ou profissional. 
Dessa maneira, com a identificação dos fatores que afetam o desempenho escolar pelo SAEB é possível a utilização de teorias, processos, métodos e instrumentos específicos para avaliar o desempenho dos estudantes; para que desta forma possa subsidiar o planejamento de políticas públicas de avaliação, a partir de constantes revisões e ajustes das políticas públicas educacionais implementadas.

Em vista disso, a partir do momento em que as políticas públicas educacionais passarem a ser fomentadas a partir de dados/indicadores estatisticamente validados, aumentar-se-ão as probabilidades de chance de serem bem-sucedidas; porque passarão a ser planejadas, executadas e acompanhadas, por um sistema capaz de informar com precisão as características da realidade educacional.

\section{Referências}

ALBERNAZ, Â.; FERREIRA, F. H. G.; FRANCO, C. Qualidade e equidade no ensino fundamental brasileiro. Pesquisa e Planejamento Econômico, Rio de Janeiro, v.32, n.3, p.453-476, dez. 2002.

ALMEIDA, A. T. C. Determinantes dos piores e melhores resultados educacionais dos alunos da rede pública de ensino fundamental no Brasil. Pesquisa e Planejamento Econômico, Rio de Janeiro, n.42, p.147-188, jan./jun.2014.

ALVES, F. Políticas educacionais e desempenho escolar nas capitais brasileiras. Cadernos de Pesquisa, São Paulo, v.38, n.134, p.413-440, mai./ago. 2008.

ASSIS, W. F. S.; SILVA, C. M. C. S. A política educacional no contexto das relações federativas. Acta Scientiarum Education, Maringá, v.39, n.2, p.185-195, abr./jun.2017.

BAUER, A.; TAVARES, M. R. Introdução. In: BAUER, A.; GATTI, B. A.; TAVARES, M. R. (Orgs.). Vinte e cinco anos de avaliação de sistemas educacionais no Brasil - origens e pressupostos. Florianópolis: Insular, 2013, p.13-18.

BONAMINO, A. C. Tempos de avaliação educacional: o SAEB, seus agentes, referências e tendências. Rio de Janeiro: Quartet, 2002.

BRASIL. [Constituição (1988)]. Constituição da República Federativa do Brasil de 1988. Brasília, DF: Presidência da República, [2018]. Disponível em: http://www.senado.gov.br/legislacao/const/con1988/CON1988_05.10.1988/CON1988.pdf. Acesso em: 12. abr. 2018.

BRASIL. Lei no 9.394, de 20 de dezembro de 1996. Estabelece as diretrizes e bases da educação 
nacional. Disponível em: http://bd.camara.leg.br. Acesso em: 12 mar. 2018.

BRASIL. Lei no 9.448, de 14 de março de 1997. Transforma o Instituto Nacional de Estudos e Pesquisas Educacionais - INEP em Autarquia Federal, e dá outras providências. Disponível em: http://www.planalto.gov.br/ccivil_03/LEIS/L9448.htm. Acesso em: 01 mar. 2018.

BRASIL. Lei no 11.274, de 6 de fevereiro de 2006. Altera a redação dos arts. 29, 30, 32 e 87 da Lei $n$ ㅇ 9.394, de 20 de dezembro de 1996, que estabelece as diretrizes e bases da educação nacional, dispondo sobre a duração de 9 (nove) anos para o ensino fundamental, com matrícula obrigatória a partir dos 6 (seis) anos de idade. Disponível em:

http://www.planalto.gov.br/ccivil_03/_ato2004-2006/2006/lei//11274.htm. Acesso em: 20 mai. 2018.

BRASIL. Lei no 11.494, de 20 de junho de 2007. Regulamenta o Fundo de Manutenção e Desenvolvimento da Educação Básica e de Valorização dos Profissionais da Educação - FUNDEB, de que trata o art. 60 do Ato das Disposições Constitucionais Transitórias; altera a Lei no 10.195, de 14 de fevereiro de 2001; revoga dispositivos da Lei $\mathrm{n}^{\circ} 9.424$, de 24 de dezembro de 1996, 10.880, de 9 de junho de 2004, e 10.845, de 5 de março de 2004; e dá outras providências. Disponível em: http://www.planalto.gov.br/ccivil_03/_ato20072010/2007/lei/l11494.htm. Acesso em: 20 mai. 2018.

BRASIL. Emenda Constitucional no 59, de 11 de novembro de 2009. Disponível em: http://www.planalto.gov.br/ccivil_03/constituicao/Emendas/Emc/emc59.htm. Acesso em: 30 jun. 2015.

BRASIL. Lei no 12.796 de 4 de abril de 2013. Altera a Lei no 9.394, de 20 de dezembro de 1996, que estabelece as diretrizes e bases da educação nacional, para dispor sobre a formação dos profissionais da educação e dar outras providências. Disponível em: http://www.planalto.gov.br. Acesso em: 01 mar. 2018.

BRASIL. Ministério do Planejamento, Orçamento e Gestão. Instituto Brasileiro de Geografia e Estatística. Síntese de indicadores sociais: uma análise das condições de vida da população brasileira 2014. Rio de Janeiro: IBGE, 2014. Disponível em: http://www.ibge.gov.br. Acesso em: 10 mai. 2016.

BRASIL. Lei no 13.005 de 25 de junho de 2014. Aprova o plano nacional de educação e dá outras providências. Disponível em: http://www.planalto.gov.br/ccivil_03/_Ato20112014/2014/Lei/L13005.htm. Acesso em: 20 dez. 2017.

BRASIL. Lei $n$ ㅇ 13.415, de 16 de fevereiro de 2017. Altera as Leis $n^{\circ}$ 9.394, de 20 de dezembro de 1996, que estabelece as diretrizes e bases da educação nacional, e 11.494, de 20 de junho 2007, que regulamenta o Fundo de Manutenção e Desenvolvimento da Educação Básica e de Valorização dos Profissionais da Educação. Disponível em: http://www.planalto.gov.br/ccivil_03/_ato2015-2018/2017/lei/l13415.htm. Acesso em: 23 mai. 2018. 
BRASIL. Decreto no 9.432, de 29 de junho de 2018. Regulamenta a Política Nacional de Avaliação e Exames da Educação Básica. Disponível em:

http://download.inep.gov.br/educacao_basica/saeb/2018/legislacao/decreto_n_9432_290620 18_regulamenta_politica_nacional_de_avaliacao_e_exames_da_educacao_basica.pdf. Acesso em: 20 dez. 2018.

BRASIL. Ministério da Educação. Instituto Nacional de Estudos e Pesquisas Educacionais Anísio Teixeira. Informações estatísticas, 2019. Disponível em: <http://portal.inep.gov.br/> Acesso em: 23 fev. 2019.

BRASIL. Portaria no 366, de 29 de abril de 2019. Disponível em: http://download.inep.gov.br/educacao_basica/saeb/2019/legislacao/portaria_n366_29042019 .pdf. Acesso em: 18 jan.2020.

CASTRO, C. M. Desenvolvimento econômico, educação e educabilidade. 2. ed. Rio de Janeiro: Tempo Brasileiro/FENAME, 1976.

CURI, A. Z.; MENEZES-FILHO, N. A relação entre educação pré-primária, salários, escolaridade e proficiência escolar no Brasil. Estudos Econômicos, São Paulo, v.39, n.4, p.811-850, out./dez. 2009.

FREITAS, D. N. T. Avaliação da educação básica no Brasil: caraterísticas e pressupostos. In: BAUER, A.; GATTI, B. A.; TAVARES, M. R. T. (Orgs.). Vinte e cinco anos de avaliação de sistemas educacionais no Brasil - origens e pressupostos. Florianópolis: Insular, 2013, p.70-96.

GATTI, B. A.; VIANNA, H. M.; DAVIS, C. Problemas e impasses da avaliação dos projetos e sistemas educacionais: dois casos brasileiros. Estudos em Avaliação Educacional, São Paulo, n.4, p.7-27, jul./dez. 1991.

GATTI, B. A. Avaliação educacional no Brasil: experiências, problemas, recomendações. Estudos em Avaliação Educacional, São Paulo, n.10, p.67-80, jul./dez. 1994.

GATTI, B. A. Avaliação de sistemas educacionais no Brasil. Sisífo - Revista de Ciências da Educação, Portugal, n.9, p.7-18, mai./ago. 2009.

GONÇALVES, F. O. O.; FRANÇA, M. T. A. Transmissão intergeracional de desigualdade e qualidade educacional: avaliando o sistema educacional brasileiro a partir do SAEB 2003. Ensaio: avaliação políticas públicas em educação, Rio de Janeiro, v.16, n.61, p.639-662 out./dez. 2008.

RIBEIRO, C. A. C. Desigualdades de oportunidades e resultados educacionais no Brasil. Dados Revista de Ciências Sociais, Rio de Janeiro, v.54, n.1, p.41-87. 2011.

SILVA, M. R.; SCHEIBE, L. Reforma do Ensino Médio; pragmatismo e lógica mercantil. Retratos da Escola, Brasília, v.11, n.20, p.19-31, jan.-jun.2017. 
SOARES, J. F.; MAROTTA, L. Desigualdades no sistema de ensino fundamental brasileiro. In: VELOSO, F. et al (Orgs.). Educação básica no Brasil. Rio de Janeiro: Elsevier, 2009. p.73-91.

SOARES, J. F.; CESAR, C. C. C.; MANBRINI, J. Determinantes de desempenho dos alunos do ensino básico brasileiro: evidências do SAEB de 1997. In: FRANCO, C. (Org.). Avaliação, ciclos e promoção na educação. Porto Alegre: Artmed, 2001. p.121-143.

VALLE, R. C. Teoria da resposta ao item. Estudos em Avaliação Educacional, São Paulo, v.21, p.7-91. 2001.

VIEIRA, S. L. A educação nas constituições brasileiras: texto e contexto. Revista Brasileira de Estudos Pedagógicos, Brasília, v.88, n.219, p.291-309, mai./ago. 2007.

Recebido em junho 2019.

Aprovado em janeiro 2020. 